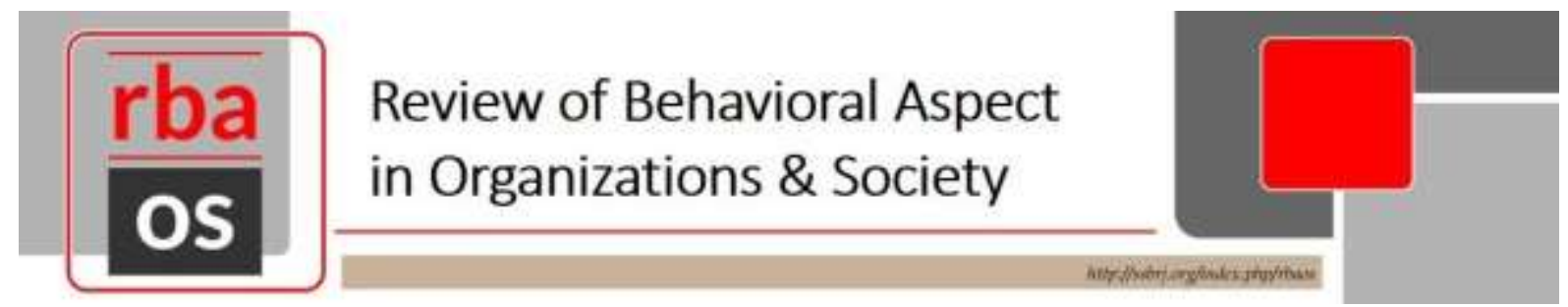

\title{
MANAGERIAL CAPABILITIES, PSYCHOLOGICAL EMPOWERMENT, ENTREPRENEURIAL INTENTION AND BUSINESS PERFORMANCE OF INFORMAL SECTOR: A STRUCTURAL EQUATION MODEL
}

\author{
Lotis Divino Cubin \\ Notre Dame of Midsayap College, Philippines
}

\begin{abstract}
This study was conducted to determine the best fit model of business performance among the informal sectors in Region 12, Philippines. A conceptual model comprising of managerial capabilities, psychological empowerment, and the entrepreneurial intention was studied to explore their relationship. The study was done in Region 12, utilizing a quantitative research approach, specifically structural equation modeling (SEM) to determine the best fit model. A total of 400 respondents participated in this study. Findings revealed that managerial capabilities, psychological empowerment, and entrepreneurial intentions significantly impact the business performance of the informal sector. Moreover, results suggested that hypothesized model 5 is the best fit model. It was also found that managerial capabilities and entrepreneurial intention significantly influence business performance. Thus, managerial capabilities and entrepreneurial intention are strong predictors of business performance among the informal sectors.

Keywords: business performance, informal sector, structural equation modeling, Philippines
\end{abstract}




\section{Introduction}

Business performance is an important subject matter for academicians, managers, and, most importantly, for entrepreneurs (Zulkiffli \& Perera, 2011). Accordingly, business performance is generally measured in terms of organizational accomplishment (González-Benito \& SuárezGonzález, 2010). In fact, studies have focused on the importance of business performance (Song, Droge, Hanvanich, Calantone, 2005; Gruber, Heinemann, Brettel, \& Hungeling, 2010; Thomas \& Theresa, 2008) as it will afford the optimal understanding of the factors which may contribute to the general performance of the business together.

In the Philippine context, the informal sector was technically termed in the Social Reform and Poverty Alleviation Act of 1988 (RA 9485) as: "poor people who run enterprises that are very small in scale and not registered with any national government agencies." Throughout the country, of the 100.98 million population, 10.5 million were recognized as informal sector operators (Philippine Statistics Authority, 2008). These business establishments and business institutions can also increase budget efficiency, consumer satisfaction, safety and market value (Valmohammadi \& Roshanzamir, 2015).

Small and Medium Enterprises (SME's) are confronted with various problems and challenges. For instance, Abdullahi, Jakada, and Kabir (2016) highlighted some business-related factors such as financing challenges, recruitment of incompetent workers, limited demand for the products sold, inadequate technology, worries on multiple tax charges, wrong location, deplorable infrastructural facilities, and limited capacity to innovate. Osalor (2012) emphasized that the most alarming problems that affect the performance of SME's are the source of funds or capitalization and the surging interest on loans that make them harder to achieve the performance they wanted to achieve (Ofoegbu, Akanbi, \& Joseph, 2013). Amongst the many points, Gano-An (2019) emphasized that informal sectors do not have formal working spaces, acclaimed non-permanency, restricted or inaccessible financing opportunities, and nonprofitability of their ventures.

Henceforth, it is on the above scenario that the researcher is prompted to measure the direct and indirect effect of managerial capabilities, psychological empowerment, entrepreneurial intention and business performance of managing proprietors of informal sector in Region XII by identifying the strongest antecedents that dynamically influence the variable that can only be determined through the use of Structural Equation Modelling approach. Moreover, this study would give enriched literature and provide knowledge in the best fit model that would contribute meaningful research findings and would benefit managing proprietors of the informal sector, government agencies, public and private sectors, students and researchers in gaining better insights and understand the importance of improving business performance.

\section{The objective of the Study}

This study intended to determine the level of business performance, psychological empowerment, and entrepreneurial intentions of the managing proprietors of informal sector in Region XII and to present the best fit model of business performance of the informal sector.

\section{Theoretical Framework}

This study is based on the resource-based theory (Wernerfelt, 1984), which outlines that the resources and capabilities of the business are the fundamental factors of business performance (Seedee, Sulaiman, \& Ismail, 2015). The resource-based theory is of great relevance in the context of small scale businesses because it contends that the long-term existence of small and medium enterprises largely is dependent on a business' distinctive product offerings, and the 
growth of this uniqueness over time is by fostering the business's core capabilities (Kelliher \& Reinl, 2009). Competence has been defined as the positioning of planned competitive priorities (strategy) and materializes the competitive priorities which are its results. A firm has a particular competence if it has a robust capacity in the field that is also considered as significant (Kim \& Arnold, 1992). These strong capabilities considered as means of achieving various activities, dependent on the available assets (Grant, 1991). Resources may be those tangible and intangible properties owned by the business. Hence, capabilities are form of the business's joint resources utilized in generating productive results.

\section{Methodology}

This study used a descriptive-correlational method. Descriptive research provides an accurate image regarding the characteristics of a particular situation and concentrates on describing the variables that exist therein (Christensen \& Burke, 2008). In a correlational study, it is frequently used to determine connections among constructs and to permit the calculation of future events from present information (Stangor, 2004). To generate the best fit model for the study, the researcher utilized a structural equation modeling (SEM) technique. Structural equation modeling or SEM is a statistical modeling technique that is viewed as a combination of factor analysis, and regression, or path analysis. The concentration of SEM is on theoretical variables represented by latent factors. The model indicates a structure for the covariances between measurable variables (Hox, Moerbeek, \& Van de Schoot, 2017). Moreover, SEM is the most suitable tool to test the observed associations among set of variables to a theoretical prediction about how these variables should be casually interrelated.

Moreover, structural equation modeling is a multifaceted method of data analysis as compared to other statistical approaches or techniques. It is a mathematical method used for defining causal conclusions from a mixture of observational data and theoretical postulations (Bhatta, Albert, Kahana, \& Lekhak, 2017; Hair, Babin \& Krey, 2017; Pearl, 2012). Structural equation modeling can be applied to conclude the interrelationships among the model variables. Through the help of structural equation modeling, relationships between and among latent and observed variables can be represented in a model and further determined. Structural equation modeling can be done in various ways. First, a model needs to be outlined. This step is called model specification. The second stage is model identification, followed by model estimation. And finally, model testing. If the model is not worthy enough to pass all the required parameters, the model should be modified and then follow the abovementioned steps again (Hasman, 2015).

\section{Results}

\section{Business Performance}

Reflected in Table 1 are the data on the level of business performance of the informal sector. The overall mean rating is 3.74 , with a standard deviation of 0.59 , described as high. This means that the informal sector agrees on the level of their performance. Sorted out from highest to lowest as follows: 3.77 or high for increase in sales, this means that despite the challenging business factors experienced by the informal sector, there was an increase of their daily sales, monthly and over the past years, 3.75 or high for profitability, 3.69 or high for innovativeness, this means that their business has been able to provide innovative products or services to customers, come out with modern technology to improve, and come out with innovative ideas in obtaining distinctive competencies than competitors. 
Table 1. Level of Business Performance

\begin{tabular}{lccc}
\hline Indicator & SD & Mean & Descriptive Level \\
\hline Increase in Sales & 0.63 & 3.77 & High \\
Profitability & 0.66 & 3.75 & High \\
Innovativeness & 0.68 & 3.6 & High \\
Overall & $\mathbf{0 . 5 9}$ & $\mathbf{3 . 7 4}$ & High \\
\hline
\end{tabular}

\section{Managerial Capabilities}

Presented in Table 2 are the data on the level of managerial capabilities of informal the sector. The overall mean rating is 3.85 , with a standard deviation of 0.46 , described as high. This means that the informal sector agrees on such capabilities. All seven indicators of managerial capabilities generated an overall mean rating of 3.85, with a standard deviation of 0.46 described as high. This means that business acumen, innovation, ownership, market orientation, results focus, perseverance, and leadership-oriented capabilities are always evident among informal sector.

Table 2. Level of Managerial Capabilities

\begin{tabular}{lllc}
\hline Indicator & SD & Mean & Descriptive Level \\
\hline Business Acumen & 0.69 & 3.80 & High \\
Innovation & 0.59 & 3.93 & High \\
Ownership & 0.65 & 4.05 & High \\
Commercial Orientation & 0.66 & 3.80 & High \\
Results Focus & 0.64 & 4.00 & High \\
Perseverance & 0.70 & 3.91 & High \\
Leadership-oriented capabilities & 0.72 & 3.63 & High \\
Overall & $\mathbf{0 . 4 6}$ & $\mathbf{3 . 8 5}$ & High \\
\hline
\end{tabular}

\section{Psychological Empowerment}

Depicted in Table 3 are the data on the level of psychological empowerment of the informal sector. The overall mean rating is 4.27 , with a standard deviation of 0.50 , described as very high. It means that the informal sector strongly agrees that they are empowered.

Table 3. Level of Psychological Empowerment

\begin{tabular}{lccc}
\hline Indicator & SD & Mean & Descriptive Level \\
\hline Meaning & 0.61 & 4.47 & Very High \\
Competence & 0.58 & 4.33 & Very High \\
Self-Determination & 0.58 & 4.22 & Very High \\
Impact & 0.69 & 4.05 & Very High \\
Overall & $\mathbf{0 . 5 0}$ & $\mathbf{4 . 2 7}$ & Very High \\
\hline
\end{tabular}

\section{Entrepreneurial Intention}

Table 4 illustrates the data on the level of the entrepreneurial intention of informal sector. The overall mean is 3.60 , with a standard deviation of 0.44 , described as high. This means that the informal sector agrees with their intention. The mean ratings are as follows: 3.54 for high on social network, this indicates that the social network of informal sector influenced their intentions toward business start-up and is strengthened by frequency of contact with their family and friends, more so, their strong ties with business-related knowledge, skills and experience provide access to specific information and resources necessary for business startup and their values, attitude, information, and skills gained from strong ties, contribute toward 
increased entrepreneurial intentions; 3.71 or high for perceived desirability, this indicates that the informal sector was attracted to start a business because of their family, friends, cultural influences and personal exposure to entrepreneurship; 3.55 or high for perceived feasibility, this indicates that the informal sector started their business because of their previous experience in business, who also believe in themselves.

Table 4. Level of Entrepreneurial Intention

\begin{tabular}{lllc}
\hline Indicator & SD & Mean & Descriptive Level \\
\hline Social Network & 0.68 & 3.54 & High \\
Perceived Desirability & 0.59 & 3.71 & High \\
Perceived Feasibility & 0.59 & 3.55 & High \\
Overall & $\mathbf{0 . 4 4}$ & $\mathbf{3 . 6 0}$ & High \\
\hline
\end{tabular}

\section{Discussion}

\section{Business Performance}

The overall high level of business performance is the result of ratings of the respondents on the variable's measurement construct like an increase in sales (high), high ratings for profitability, and innovativeness, which has a high level as well. This denotes that their business was able to make profit daily despite the external business factors. This rating supported the idea of Ngek (2015), who posited that performance of small scale business is a key concern and wide as they assume a vital job in supporting financial development and advancement. Since independent ventures assume a huge job in the economy, their performance is firmly connected with the performance of the economy as well (Islam, Khan, Obaidullah, \& Alam, 2011). Organizations gain and support competitive edge because of the capacity to re-establish, incorporate and extend their current abilities, which empower the firm to continue and increment firm performance (Sok, O’Cass, \& Sok, 2013).

\section{Managerial Capabilities}

The level of managerial capabilities is high, which indicates that respondents have a clear understanding of the key business drivers inside the organization. Supporting the previous studies of Ahmed (2017) who proposed that the businesses are appreciated based on their capabilities. The excellent managerial capabilities can be attained because of the investment in human capital through developing managerial skills and knowledge (King, Hebl, George, \& Matusik, 2010).

\section{Psychological Empowerment}

The overall high rating on psychological empowerment is incongruent with the empirical findings of Rababah (2017) who posited that psychological empowerment could improve directly and indirectly on the business' performance. Besides, empowerment has been greatly utilized and recognized in the across disciplines (Pranic \& Roehl, 2012). According to Llorente-Alonso and Topa (2018) psychological empowerment is considered an inspirational concept of self-effectiveness to allow workers to have their initiatives.

\section{Entrepreneurial Intention}

The respondent rated entrepreneurial intention as a high level, and this means that social network is influenced own intentions toward business start-up. Supporting the study of Mappigau, Ir, and Maupa (2012), both internal and external aspects of entrepreneurial intention significantly influence the growth of small and medium businesses directly and positively. Moreover, from the findings of the study of Giagtzi (2013) they specified that positive perceptions of feasibility and desirability increased self-employment intents. An individual 
may have the capability of being business visionary in light of the fact that he possesses competency and self-viability yet may not make the change into enterprise due to an absence of intention (Krueger, Hansen, Michl, \& Welsh, 2011).

\section{The best fit model for business performance of the informal sector}

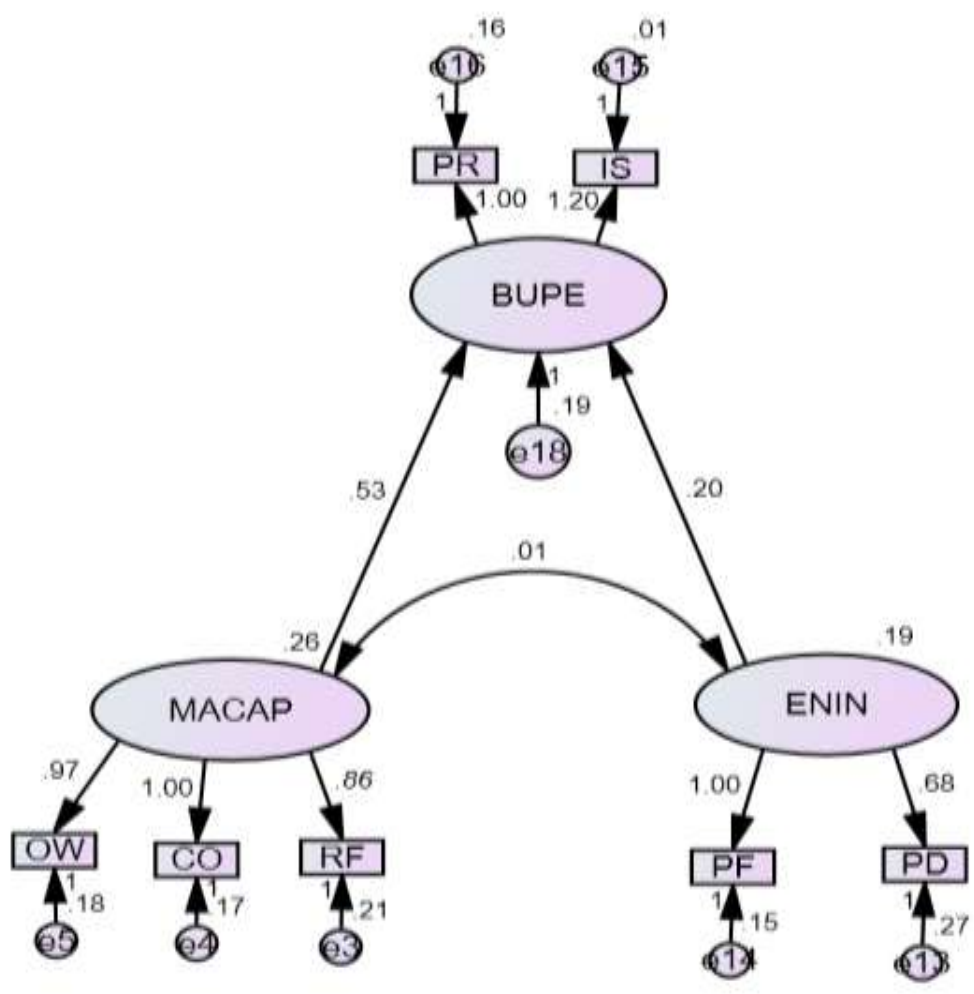

Figure 1. The Best Fit Model

The model clearly exemplifies the position of managerial capabilities and entrepreneurial intention as predictors of business performance. However, it could be gathered from the model that out of the seven indicators of managerial capabilities, only three remained as significant predictors of business performance to wit; ownership, market orientation, and results focus. For entrepreneurial intention, only two out of three indicators were found to affect business performance namely: perceived feasibility and perceived desirability. On the part of the business performance, only two out of three indicators remained to be measured; these are profitability and increase in sales. Therefore, the findings suggest that business performance of informal sector was best anchored on: managerial capabilities, which was measured in terms of ownership, market orientation and results focus, and entrepreneurial intention, which was measured in terms of perceived feasibility and perceived desirability.

\section{Conclusion}

Based on the findings of the study, the following conclusions were drawn. The respondents perceived that the level of business performance was high, which means that the informal sector agreed on such performance. The respondents observed a very high level of psychological empowerment, which showed that it was strongly agreed by the entrepreneurs in the informal sector. The respondents manifested a high level of managerial capabilities, which means that the informal sector agreed on the level of such capabilities. A high level of entrepreneurial intention on the part of the respondents means that it is agreed by the informal sector. 


\section{Recommendations}

Based on the results of the study, the researcher proposes the following recommendations: For the non-government organizations that help alleviate the condition of the informal sector of the society, they may consider looking into this situation and pour out whatever aide they can provide to this sector. Based on the findings, it can be seen that at some point, they are innovative and practiced the leadership capabilities that a particular entrepreneur necessitates. Aside from their earning capacity, there is a need to help this sector as most of them were living below the poverty line.

Then, local government units may subsidize their operations utilizing the local fund for commerce \& development to further develop their entrepreneurial abilities and innovative skills. This is very important as businesses are exponentially increasing, and competition is getting tougher. As shown in the results, informal sectors are good sources of innovation and innovative ideas may help them achieve success in their entrepreneurial ventures.

On the other hand, the local economic enterprise office may lend help in the form of financial and technical assistance for them to reach the highest level of performance. This study clearly emphasizes the fact that entrepreneurs of the informal sector have strong willingness to engage in business as it showed that their entrepreneurial intention is of high level and is correlated with business performance. Efforts to strengthen the informal sector and allowed them to make some representations in the business environment needs to be carried and intensified.

Most importantly, a sound economic policy intended for the informal sectors must be embraced by each governmental subdivision that will allow a home-based producer in the value chain process, that will permit the sidewalk vendor to participate in formal trading and that they will have an equal opportunity with large players on the incentives and aid of the government.

\section{References}

Abdullahi, M. S., Jakada, B. A., \& Kabir, S. (2016). Challenges affecting the performance of Small and Medium Scale Enterprises (SMEs) in Nigeria. Journal of Human Capital Development (JHCD), 9(2), 21-46.

Ahmed, K. A. (2017). The influence of development on managerial capabilities and performance: Empirical evidence from Pakistan. Journal of Southeast Asian Research, 20, 1-12.

Bhatta, T. R., Albert, J. M., Kahana, E., \& Lekhak, N. (2017). Early origins of later life psychological well-being: A novel application of causal mediation analysis to life course research. The Journals of Gerontology, 73(1), 160-170.

Christensen, L. \& Burke, J. (2008). Educational research: Quantitative, qualitative, and mixed approaches. California: SAGE Publications, Inc.

Gano-An, J.C. (2019). On becoming creative solopreneurs: A case of rural peddlers. Review of Integrative Business and Economics Research, 8, 119-133.

Giagtzi, Z. (2013). How perceived feasibility and desirability of entrepreneurship influence entrepreneurial intentions: A comparison between southern and northern European countries. Master thesis. Erasmus Universiteit Rotterdam, Erasmus School of Economic.

González-Benito, J., \& Suárez-González, I. (2010). A study of the role played by manufacturing strategic objectives and capabilities in understanding the relationship between Porter's generic strategies and business performance. British Journal of Management, 21(4), 1027-1043.

Grant, R. M. (1991). Analyzing resources and capabilities, contemporary strategic analysis: Concepts, techniques and applications. Cambridge, MA: Blackwell. 
Gruber, M., Heinemann, F., Brettel, M., \& Hungeling, S. (2010). Configurations of resources and capabilities and their performance implications: An exploratory study on technology ventures. Strategic Management Journal, 31(12),1337-1356.

Hair, J. F., Babin, B. J., \& Krey, N. (2017). Covariance-based structural equation modeling in the journal of advertising: Review and recommendations. Journal of Advertising, 46(1), 163-177.

Hasman, A. (2015). An introduction to structural equation modeling. Retrieved from

Hox, J. J., Moerbeek, M., \& Van de Schoot, R. (2017). Multilevel analysis: Techniques and applications. London, England: Routledge.

https://apps.dtic.mil/docs/citations/ADA557445

https://psa.gov.ph/content/annual-poverty-indicators-survey-apis

https://www.researchgate.net/profile/Mahmoud_Abd_Al_Rahman/publication/326573

068_Implementing_customer_relationship_management_in_governmental_organizati

ons/links/5b57023caca27217ffb72b19/Implementing-customer-relationship-

management-in-governmental-organizations.pdf

https://www.researchgate.net/profile/Mohamed_Khalifa9/publication/326258052_Hea

lthcare_IT_Strategic_Alignment_Challenges_and_Recommendations/links/5b416066

aca2728a0d618ee9/Healthcare-IT-Strategic-Alignment-Challenges-and-

Recommendations.pdf

Islam, M. A., Khan, M. A., Obaidullah, A. Z. M., \& Alam, M. S. (2011). Effect of entrepreneur and firm characteristics on the business success of small and medium enterprises (SMEs) in Bangladesh. International Journal of Business and Management, 6(3), 289299.

Kelliher, F., \& Reinl, L. (2009). A resource-based view of micro-firm management practice. Journal of Small Business and Enterprise Development, 16(3), 521-532.

Kim, J.S., \& Arnold, P. (1992). Manufacturing competence and business performance: A framework and empirical analysis. International Journal of Operations and Production Management, 13(10), 4-25.

King, E. B., Hebl, M. R., George, J. M., \& Matusik, S. F. (2010). Understanding tokenism: Antecedents and consequences of a psychological climate of gender inequity. Journal of Management, 36, 482-510.

Krueger, N., Hansen, D. J., Michl, T., \& Welsh, D. H. (2011). Thinking "sustainably”: The role of intentions, cognitions, and emotions in understanding new domains of entrepreneurship. Bingley: Emerald Group Publishing Limited.

Llorente-Alonso, M., \& Topa, G. (2018). Prevention of occupational strain: Can psychological empowerment and organizational commitment decrease dissatisfaction and intention to quit? Journal of Clinical Medicine, 7(11), 450

Mappigau, P., Ir, S. U., \& Maupa, H. (2012). Entrepreneurial intention and small business growth: An empirical study of small food processing enterprises in South Sulawesi, Indonesia. International Journal of Business and Social Research, 2(4),237-248.

Ngek, N. B. (2015). Entrepreneurial self-efficacy and small business performance: The mediating effect of entrepreneurial mindset and openness to experience. Problems and Perspectives in Management, 13(4), 271-280.

Ofoegbu, E. O., Akanbi, P. A., \& Joseph, A. T. (2013). Effect of contextual factors on the performance of SMEs in Nigeria: A case study of Ilorin Metropolis. Advance in Management and Applied Economics, 3(1), 95-114.

Osalor, P. (2012). Contributions of SMEs to the Nigerian economy. Retrieved from http://www.successinyourbusiness.com/contribution_of_smes_to_the_nigerian_econo my 
Pearl, J. (2012). The causal foundations of structural equation modeling. Retrieved from performance: An empirical study of SMEs in Saudi Arabia. Retrieved from

Philippine Statistics Authority. (2008). Annual poverty indicators survey. Retrieved from

Pranic, L., \& Roehl, W. S. (2012). Rethinking service recovery: A customer empowerment (CE) perspective. Journal of Business Economics and Management, 13(2), 242-260.

Rababah, N. M. (2017). The role of psychological empowerment and innovation on firm

Seedee, R., Sulaiman, M., \& Ismail, I. (2015). Best business practices and performance in ceramics industry in Thailand. 9Th Global Conference on Business and Economics. Paper presented at University UK, United Kingdom.

Sok, P., O’Cass, A., \& Sok, K. M. (2013). Achieving superior SME performance: Overarching role of marketing, innovation, and learning capabilities. Australasian Marketing Journal (AMJ), 21(3), 161-167.

Song, M., Droge, C., Hanvanich, S. \& Calantone, R. (2005). Marketing and technology resource complementarity: An analysis of their interaction effect in two environmental contexts. Strategic Management Journal, 26(3), 259-276.

Stangor, C. (2004). Research methods for the behavioral sciences. 2nd Ed. New York: Houghton Mifflin.

Thomas, W. Y. M., Theresa, L., \& Ed, S. (2008). Entrepreneurial competencies and the performance of small and medium enterprises: An Investigation through a framework of competitiveness. Journal of Small Business and Entrepreneurship, 21(3), 257.

Valmohammadi, C., \& Roshanzamir, S. (2015). The guidelines of improvement: Relations among organizational culture, TQM and performance. International Journal of Production Economics, 164,167-178.

Wernerfelt, B. (1984). A resource-based view of the firm. Strategic Management Journal, 5(2), 171-180.

Zulkiffli, S. N. A., \& Perera, N. (2011). A Literature Analysis on Business Performance For SMEs: Subjective or Objective Measures?. In Society of Interdisciplinary Business Research (SIBR) 2011 Conference on Interdisciplinary Business Research. 
